\title{
PENGGUNAAN DATA ENVELOPMENT ANALYSIS (DEA) DALAM PENGUKURAN EFISIENSI BANK UMUM SYARIAH DI INDONESIA
}

\author{
Anita Puspitasari, Didit Purnomo dan Triyono \\ Universitas Muhammadiyah Surakarta \\ E-mail: anitapuzpit@gmail.com,dp274@ums.ac.id
}

\begin{abstract}
The purpose of the research is to analayze efficiency level of Sharia Commercial Bank in Indonesia (Bank Mega Syariah, Bank Muamalat Indonesia, Bank Panin Dubai Syariah, Bank BNI Syariah, Bank BRI Syariah, and Bank Syariah Mandiri) 2014-2015 period. Data used in this research is secondary data taken from Financial Statement Publication issued by Otoritas Jasa Keuangan (OJK). This research uses input-output variable with Data Envelopment Analysis (DEA) Method.The result shows the difference of efficiency score for each Sharia Commercial Bank. Based on the calculacy using Data Envelopment Analysis (DEA) Method on BUSN Foreign Exchange of Sharia Commercial Bank in Indonesia only Bank Panin Dubai Syariah that has been succeeded with 100 percent of continuously efficiency during the research. The highest efficiency is experienced by Bank BNI Syariah and BRI Syariah because during the research they experienced inefficiency. During the research Bank Mega Syariah experienced efficiency three times on quarter March 2014, March 2015, and June 2015. Bank Muamalat Indonesia only experienced efficiency twice on quarter March 2014 and March 2015, beside that Bank Muamalat Indonesia experienced inefficiency. Bank Syariah Mandiri experienced efficiency twice on quarter March 2015 and quarter December 2015.
\end{abstract}

Keywords: Sharia Commercial Bank, Efficiency, Data Envelopment Analysis (DEA)

\section{A. Pendahuluan}

Pada tahun 1997 terjadi krisis moneter yang membuat bankbank konvensional saat itu berjumlah 240 mengalami negative spread yang berakibat pada likuidasi, kecuali perbankan yang 
menggunakan prinsip syariah. Pada bulan November 1997, 16 bank ditutup (dilikuidasi), berikutnya 38 bank, selanjutnya 55 buah bank masuk kategori BTO dalam pengawasan BPPN. Namun, kondisi itu berbeda dengan perbankan yang menggunakan prinsip syariah. Hal ini disebabkan oleh Bank Syariah tidak dibebani oleh nasabah membayar bunga simpanannya, melainkan Bank Syariah hanya membayar bagi hasil yang jumlahnya sesuai dengan tingkat keuntungan yang diperoleh dalam sistem pengelolaan perbankan syariah. Sistem bagi hasil tersebut, jelas bahwa perbankan yang menggunakan prinsip syariah dapat selamat dari negative spread; sedangkan bank-bank yang lain bisa selamat karena bantuan pemerintah (BLBI) 700-an triliun rupiah yang sampai hari ini bermasalah. Kalau tidak ada BLBI dan rekapitalisasi, berupa suntikan obligasi dari pemerintah, niscaya semua bank konvensional gulung tikar karena dilikuidasi.

Bank syariah membuktikan sebagai lembaga keuangan yang dapat bertahan ditengah krisis perekonomian yang melanda negara semakin parah. Pada tahun 2008 kondisi ekonomi global mengalami goncangan krisis, yang berawal ketika Amerika Serikat gagal mengelola usaha property, sehingga berdampak pada laju perekonomian dalam negeri meningkat. Inflasi yang tinggi akan mempengaruhi pertumbuhan ekonomi negara mengalami perlambatan. Pada tahun 2011 Indonesia berhasil mengantisipasi krisis ekonomi yang stabil laju inflasi sebesar 3,79\%. Perbankan syariah yang dapat bertahan dalam kondisi perekonomian yang buruk. Oleh karena pembiayaan perbankan syariah yang masih lebih diarahkan kepada aktivitas perekonomian domestik, sehingga belum memiliki tingkat integrasi yang tinggi dengan sistem keuangan global (Ali, 2008).

Efisiensi adalah istilah yang digunakan untuk mengukur kemampuan pengelolaan atau pemanfaatan asset produksi. Oleh karena itu, efisiensi ini berkaitan dengan bagaimana layaknya suatu asset dikelola. Semakin mendekati ideal, dikatakan semakin efisien dan sebaliknya (Noor, 2007). Efisiensi dalam dunia perbankan adalah indikator penting dalam melihat kemampuan bank syariah untuk bertahan dan menghadapi persaingan industri perbankan di Indonesia. Efisiensi dalam perbakankan juga merupakan salah satu 
parameter kinerja yang cukup popular, banyak digunakan karena merupakan jawaban atas kesulitas-kesulitan dalam menghitung ukuran-ukuran kinerja perbankan. Kemampuan menghasilkan output yang maksimal dengan input yang ada merupakan ukuran kinerja yang diharapkan. Pada saat pengukuran efisiensi dilakukan menurut Astiyah dan Jardin (2006) bank dihadapkan pada kondisi bagaimana mendapatkan tingkat output yang optimal dengan tingkat input yang ada, atau tingkat input yang minimum dengan tingkat output tertentu. Dengan diidentifikasikannya alokasi input dan output, dapat dianalisa lebih jauh untuk melihat penyebab ketidak efisienan. (Gumilar dan Komariah, 2011)

Awalnya evaluasi kinerja efisiensi diukur dengan menggunakan rasio keuangan, tetapi menurut beberapa pakar penilaian efisiensi tidak bisa dilakukan secara parsial tetapi harus memperhitungkan seluruh output dan input yang ada. Maka digunakan pendekatan parametrik dan non parametrik. Analisis parametrik yang paling populer menurut Yuniarti (2008) adalah Stochastic Frontier (SFA), sedang yang non parametrik adalah Data Envelopment Analysis (DEA). Karakter pengukuran efisiensi dengan metode DEA menurut Muharam dan Pusvitasari (2007) memiliki konsep yang berbeda dengan efisiensi pada umumnya yaitu pertama, efisiensi yang diukur adalah bersifat teknis, bukan ekonomis, artinya bahwa analisis DEA hanya memperhitungkan nilai absolut dari suatu variabel. Kedua, nilai efisiensi yang dihasilkan bersifat relatif atau berlaku dalam lingkup sekumpulan UKE (Unit Kegiatan Ekonomi).

Sesuai dengan fenomena yang telah dijelaskan, tujuan penelitian ini adalah mengukur tingkat efisiensi Bank Umum Syariah (BUS) di Indonesia di mana perbankan syariah di Indonesia semakin berkembang dalam upaya mencapai target market share yang lebih besar agar dapat lebih bersaing dengan bank konvensional.

\section{B. Pengertian Bank Syariah}

Setelah diberlakukannya UU Nomor 10 Tahun 1998 tentang perubahan UU Nomor 7 Tahun 1992 tentang perbankan telah memberi kesempatan luas untuk pengembangan jaringan perbankan syariah. Menurut Undang-undang Nomor 10 tahun 1998 
bank syariah adalah bank yang melaksanakan kegiatan usahanya berdasarkan prinsip syariah yang dalam kegiatannya memberikan jasa dalam lalu lintas pembayaran.

Bank syariah adalah suatu lembaga keuangan yang berfungsi sebagai perantara bagi pihak yang berkelebihan dana dengan pihak yang kekurangan dana untuk kegiatan usaha dan kegiatan lainnya sesuai dengan hukum Islam. Selain itu, bank syariah biasa disebut Islamic banking atau interest fee banking, yaitu suatu sistem perbankan dalam pelaksanaan operasional tidak menggunakan sistem bunga (riba), spekulasi (maisir), dan ketidakpastian atau ketidakjelasaan (gharar). (Ali, 2008: 1)

Ayat yang menjelaskan mengenai larangan riba yaitu Q.S. Ali-Imran ayat 130 yang artinya :"Hai orang-orang yang berima, janganlah kamu memakan riba dengan berlipat ganda dan bertawakallah kamu kepada Allah supaya kamu mendapat keberuntungan"

\section{Efisiensi}

Efisiensi adalah istilah yang digunakan untuk mengukur kemampuan pengelolaan atau pemanfaatan asset produksi. Semakin mendekati ideal, dikatakan semakin efisien, dan sebaliknya. Oleh karena itu, efisiensi ini berkaitan dengan bagaimana selayaknya suatu asset dikelola. Pengukuran ini diperlukan untuk banyak hal dalam rangka pengembangan bisnis. Efisiensi diukur dengan bagaimana selayaknya, atau bagaimana idealnya penggunaan asset atau membatasi hal-hal yang mubazir. Oleh Karena itu efisiensi ini berkaitan dengan rantai nilai (value chain), yaitu keterkaitan antar aktifitas yang dilakukan dalam menciptakan barang dan jasa. (Noor, 2007:399)

Pengukuran model efisiensi menurut Zahro (2012) dapat dilihat melalui dua pendekatan, antara lain:

\section{Pendekatan Sisi Input}

Pendekatan ini digunakan untuk menjawab berapa banyak kuantitas input dapat dikurangi secara proporsional untuk memproduksi kuantitas output yang sama. Pendekatan ini 
digunakan apabila kondisi pasar telah mengalami tingkat jenuh sehingga perusahaan perlu mengetahui tingkat efisiensi dari sumber daya yang ada pada saat ini.

\section{Pendekatan Sisi Output}

Pendekatan ini menjawab berapa banyak kuantitas output dapat ditingkatkan secara proporsional untuk memproduksi kuantitas input yang sama. Pendekatan sisi output ini diguinakan pada saat kondisi pasar masih bagus sehingga produsen diharapkan dapat mempertahankan atau bahkan meningkatkan output dengan input yang sama.

Selanjutnya, menurut Muharam dan Pusvitasari (2007) terdapat 3 pendekatan yang lazim digunakan dalam metode parametricStochastic Frontier Approach (SFA) dan Distribution Free Approach (DFA) dan metode non-parametrik DEA untuk mendefinisikan hubungan input dan output dalam kegiatan finansial suatu lembaga keuangan:

\section{a. Pendekatan Aset (The Assets Approach)}

Pendekatan ini mencerminkan fungsi primer suatu lembaga keuangan sebagai pencipta kredit pinjaman (loans). Dalam pendekatan asset ini, output benar-benar didefinisikan ke dalam bentuk asset.

\section{b. Pendekatan Peoduksi (The Production Approach)}

Pendekatan Produksi menganggap lembaga keuangan sebagai produsen dari akun deposito (deposits account) dan kredit pinjaman (credit account) lalu mendefinisikan output sebagai jumlah tenaga kerja, pengeluaran modal pada asset-aset tetap dan materialnya.

\section{c. Pendekatan Intermediasi (The Intermediation Approach)}

Pendekatan internediasi memandan sebuah lembaga keuangan sebagai intermediator, yaitu merubah dan mentransfer aset-aset keuangan dari unit-unit surplus menjual unit-unit deficit. Dalam hal ini inpit-input institusional seperti biaya tenaga kerja, modal dan pembayaran bunga pada deposit, lalu pengukuran output dalam bentuk kredit pinjaman (loans) dan investasi keuangan (financial investment). Akhirnya pendekatan intermediasi 
melihat fungsi primer sebuah institusi keuangan pencipta kredit pinjaman (loans).

Pendekatan yang digunakan dalam penelitian ini adalah pendekatan intermediasi. Pendekatan intermediasi digunakan dalam penelitian karena mempertimbangkan fungsi vital bank sebagai financial intermediation yang menghimpun dana dari surplus unit dan menyalurkannya kepada deficit unit. Pertimbangan lainnya adalah karakteristik dan sifat dasar bank yang melakukan transformasi asset yang berkualitas dari simpanan yang dihimpun menjadi kredit yang disalurkan ke masyarakat.

Penelitian Firdaus dan Hosen dalam Buletin Ekonomi Moneter dan Perbankan (2013) tentang Efisiensi Bank Umum Syariah menggunakan pendekatan Two-Stage Data Envelopment Analysis menjelaskan bahwa tingkat efisiensi 10 BUS memiliki trend yang fluktuatif selama waktu penelitian. Secara parsial, Bank Muamalat Indonesia memiliki tingkat efisiensi rata-rata paling tinggi, dan Bank Victoria Syariah memiliki tingkat efisiensi paling rendah. Variabel Cabang Bank, NPF, CAR memiliki pengaruh negatif dan signifikan terhadap tingkat efisiensi bank. Variabel Aset, ROA, ROE memiliki pengaruh positif dan signifikan.

Harjun Muharam dan Rizki Pusvitasari dalam penelitian mengenai Perbandingan Efisiensi Bank Syariah di Indonesia mencatat hanya 3 bank yang senantiasa dalam kondisi efisien 100\% yaitu BTN Syariah, Niaga Syariah daan Permata Syariah. Sembilan bank lainnya dalam sampel memiliki kondisi efisien. Dengan tidak ditemukannya perbedaan nilai efisiensi secara signifikan pada masing-masing Bank Syariah yang ada di Indonesia, maka hal ini mengindikasikan bahwa fungsi intermediasi yang dijalankan oleh bank-bank syariah yang ada di Indonesia secara merata telah berjalan dengan baik.

Fadzlan, dkk (2007) dalam penelitiannya yang berjudul The Efficiency of Islamic Banks: Empirical Evidence from the MENA and Asian Countries Islamic Bank Sectors dengan variabel inputnya financing, investment, income dan variabel outputnya deposits, assets. Shafitranata (2011) melakukan penelitian tentang Tingkat Efisiensi Bank Umum Syariah (BUS) menghasilkan rata-rata tingkat efisiensi 
rata-rata tahunan BMI, BSM, dan BMS mencapai efisiensi suatubank kecuali BMS yang memiliki rata-rata tahunan kurang dari tetapan suatu efisien

Penelitian ini menggunakan metode analisis kuantitatif, yaitu dalam pengelolaan data berupa input dan output yang diambil dari neraca keuangan dan laporan laba-rugi yang dimiliki oleh masing-masing bank. Dalam analisis ini menggunakan Data Envelopment Analysis (DEA) di mana DEA merupakan metode yang telah terstandarisasi sebagai alat untuk pengukuran kinerja suatu aktivitas unit dengan proses pengolahan menggunakan perangkat lunak DEAP 2.1. Selain itu, sebagai perangkat lunak pendukung peneliti menggunakan perangkat lunak Ms. Excel.

Penelitian ini mengambil BUSN Devisa Bank Umum Syariah di Indonesia sebagai objek penelitian. Sampel yang digunakan dalam penelitian ini yaitu Bank Mega Syariah, Bank Muamalat Indonesia, Bank Syariah Mandiri, Bank BNI Syariah, Bank BRI Syariah, dan Bank Panin Dubai Syariah periode 20142015. Penelitian ini menggunakan jenis penelitian kuantitatif, yaitu sumber data di ambil dari variabel input-output dalam neraca dan laporan keuangan laba/rugi masing-masing Bank Umum Syariah yang telah diterbitkan oleh Otoritas Jasa Keuangan (OJK) sebagai institusi yang menerbitkan seluruh laporan keuangan perbankan syariah di Indonesia.

\section{D.Model-Model Data Envelopment Analysis (Dea)}

Dalam model DEA menurut Nizar (2015) terdapat dua pendekatan optimasi yang biasa digunakan, yaitu :

\section{Constan Return to Scale (CRS)}

Model CCR yang merupakan model dasae DEA menggunakan asumsi constan return to scale yang membawa implikasi pada bentuk efficient set yang linier. Model constan return to scale dikembangkan oleh Climes, Cooper dan Rhodes (model CCR), model ini mengasumsikan bahwa rasio antara penambahan input dan output adalah sama (constan return to scal). Artinya jika ada tambahan input sebesar $\mathrm{x}$ kali, maka output akan meningkay sebesar $x$ kali juga. Asumsi lain yang digunakan pada model ini 
adalah bahwa setiap perusahaan atau unit pembuat keputusan (UPK) beroperasi pada skala yang optimal.

\section{Variable Return to Scale}

Model ini dikembangkan oleh Banker, Charnes Cooper pada tahun 1984 dan merupakan pengembangan model CCR. Model ini beranggapan bahwa perusahaan tidak atau belum beroperasi pada skala yang optimal, asumsi dari model ini adalah rasio antaa penambahan input dan output tidak sama (variable return to scale). Artinya, penambahan input $\mathrm{x}$ kali tidak akan menyebabkan output naik sebesar $\mathrm{x}$ kali, bisa lebih kecil atau lebih besar dari $\mathrm{x}$ kali.

\section{E. Pembahasan}

Pada penelitian ini digunakan data triwulanan Bank Umum Syariah yaitu Bank Mega Syariah, Bank Muamalat Indonesia, Bank Panin Dubai Syariah, Bank BNI Syariah, Bank BRI Syariah, dan Bank Syariah Mandiri pada peridoe 2014-2015. Penelitian ini memiliki tujuan untuk mengukur tingkat efisiensi Bank Umum Syariah menggunakan Data Envelopment Analysis (DEA), yaitu dengan pendekatan intermediasi sebagai pendekatan dalam penentuan variabel input dan outputnya. Dengan pendekatan intermediasi digunakan variabel simpanan, biaya tenaga kerja, dan biaya operasional lain sebagai variabel input dan pembiayaan dan pendapatan operasional lain sebagai variabel output.

Dalam pengukuran tingkat efisiensi Bank Umum Syariah (BUS) di Indonesia, peneliti menggunakan perangkat lunak DEAP 2.1 dan Microsoft Excel sehingga peneliti tidak melakukan perhitungan secara manual.

Bank umum syariah yang dijadikan sampel dalam penelitian ini adalah BUSN Devisa Bank Umum Syariah yang terdiri dari Bank Mega Syariah, Bank Muamalat Indonesia, Bank Panin Dubai Syariah, Bank BNI Syariah, Bank BRI Syariah, dan Bank Syariah Mandiri. Variabel yang digunakan dalam penelitian ini adalah tiga variabel input dan dua variabel output. Variabel input yang digunakan adalah simpanan, biaya tenaga kerja, dan biaya operasional lainnya, sedangkan variabel output yang digunakan adalah pembiayaan dan pendapatan operasional lain. 
Berdasarkan hasil perhitungan dengan menggunakan DEA, maka diketahui skor efisiensi dari masing-masing bank umum syariah yang dijadikan sampel. Hasil perhitungan tersebut menggambarkan pencapaian efisiensi masing-masing bank umum syariah pada tahun 2014-2015.

Bank umum syariah yang mempunyai skor 1 selama triwulan Maret 2014 sampai triwulan Desember 2015 dikatakan efisien. Bank umum syariah yang dikatakan efisien adalah Bank Panin Dubai Syariah. Sedangkan Bank Syariah Mandiri hampir mendekati efisien karena hanya 2 triwulan saja yang mengalami inefisiensi yaitu pada triwulan Maret 2015 dengan skor efisiensi 0,717 dan triwulan Desember 2015 dengan skor efisiensi 0,497. Bank BRI Syariah dan Bank BNI Syariah selama triwulan Maret 2014 sampai triwulan Desember 2015 mengalami inefisiensi. Bank Mega syariah mengalami inefisiensi pada triwulan Maret 2014, triwulan Maret 2015, dan triwulan Juni 2015, sedangkan Bank Muamalat Indonesia hanya mengalami efisiensi pada triwulan Maret 2014 dan triwulan Maret 2015. Bank umum syariah dikatakan efisiensi apabila skor efisiensinya bernilai 1 dan dikatakan inefisiensi bila skor efisiensinya kurang dari 1.

\section{F. Simpulan}

1. Berdasarkan perhitungan dengan menggunakan Data Envelopment Analysis (DEA) yaitu pada BUSN Devisa Bank Umum Syariah di Indonesia (Bank Mega Syariah, Bank Muamalat Indonesia, Bank Syariah Mandiri, Bank BNI Syariah, Bank BNI Syariah, Bank Panin Dubai Syariah) hanya Bank Panin Dubai Syariah yang sudah 100 persen mengalami efisiensi terus menerus dari periode penelitian yaitu pada maret 2014-desember 2015.

2. Bank yang mengalami inefisiensi tertinggi yaitu Bank BNI Syariah dan BRI Syariah karena selama periode penelitian yaitu pada maret 2014-desember 205 mengalami inefisiensi.

3. Bank Mega Syariah selama periode penelitian mengalami efisiensi sebanyak 3 kali yaitu pada triwulan Maret 2014 dengan tingkat efisiensi sebesar 0,927, triwulan Maret 2015 
dengan tingkat efisiensi sebesar 0,269 , dan triwulan Juni 2015 dengan tingkat efisiensi sebesar 0,472.

4. Bank Muamalat Indonesia selama periode penelitian hanya mengalami efisiensi sebanyak 2 kali yaitu pada triwulan Maret 2014 dan triwulan Maret 2015. Triwulan Juni 2014 memiliki tingkat efisiensi sebesar 0,721, triwulan September 2014 memiliki tingkat efisiensi sebesar 0,948, triwulan Desember 2014 memiliki tingkat efisiensi sebesar 0,832, triwulan Juni 2015 memiliki tingkat efisiensi sebesar 0,741, triwulan September 2015 memiliki tingkat efisiensi sebesar 0,858, dan triwulan Desember 2015 memiliki tingkat efisiensi sebesar 0,690.

5. Bank Syariah Mandiri selama periode penelitian mengalami inefisiensi sebanyak 2 kali yaitu pada triwulan Maret 2015 dengan tingkat efisiensi sebesar 0,717 dan triwulan Desember 2015 dengan tingkat efisiensi sebesar 0,497. 
Penggunaan Data Envelopment Analysis...

\section{DAFTAR PUSTAKA}

Al-Qur'an

Ali, Zainuddin. 2008. HukumPerbankanSyariah. Jakarta :SinarGrafika

Astiyah, S. dan Husman, A. J. 2006. Fungsi Intermediasi dalam Efisiensi Perbankan di Indonesia: Derivasi Fungsi Profit. Paper dalam Buletin Ekonomi Moneter dan Perbankan pada bulan Maret 2006. Jakarta: Prenada Media Group.

Azaro, Siti Fatimah. 2014. Analisis Mengukur Tingkat Efisiensi Perbankan Syariah di Indonesia (Studi Pada Bank Syariah Mandiri, Bank Mega Syariah, Bank Muamalat Indonesia Periode 20092012). Surakarta: Skripsi S1 Universitas Muhammadiyah Surakarta.

Gumilar, Ivan dan Komariyah, Siti. 2011. Pengaruh Efisiensi Kinerja Dengan Metode Stochastic Frontier Approach Pada Perbankan Syariah. Jurnal Manajemen dan Bisnis, Vol. 7 No. 2, Januari 2011

Hassan, M. Kabir. 2006. The X-Efficiency in Islamic Banks. Islamic Economic Studies. Vol. 13, No. 2, February 2006

Iswahyudhi, Febriyan. 2015. Analisis Perbankan Syariah di Indonesia Menggunakan Metode Data Envelopment Analysis (DEA) Pada Tahun 2010-2014). Surakarta: Skripsi S1 Universitas Muhammadiyah Surakarta.

Janwari, Yadi. 2015. Lembaga Keuangan Syariah. Bandung: PT Remaja Rosdakarya Offset

Kasmir. 2012. Manajemen Perbankan edisi revisi. Jakarta: Raja Grafindo Persada.

Muhammad. 2005. Manajemen Bank Syariah. Yogyakarta : UPP AMP YKPN.

Muharam, H. dan Pusvitasari, R. 2007. Analisis Perbandingan Efisiensi Bank Syariah di Indonesia Dengan Metode Data Envelopment Analysis (DEA) (Periode Tahun 2005). Vol. II No. 3. Jurnal Fakultas Ekonomi UNDIP, Desember 2007. hlm. 80-116 
Nadratuzzaman Hosen, Hilda dan Hasan Ali. 2006. Lembaga Bisnis Syariah cetakan ke II. Jakarta: Pusat Komunikasi Ekonomi Syariah (PKES)

Nizar, Ahmad. 2015. Analisis Tingkat Efisiensi Bank Umum Syariah Sebelum dan Sesudah Spin Off. Jakarta: UIN Syarif Hidayatullah.

Noor, Henry Faizal. 2007. Ekonomi Manajerial. Jakarta: PT Raja Grafindo Persada.

Otoritas Jasa Keuangan. 2016. Laporan Keuangan Publikasi. http:/ / www.ojk.go.id.Diakses pada 20 Desember 2016

Rifai, Veithzal dan Arfian Arifin. 2007. Bank and Financial Institute Management. Jakarta: PT Raja GrafindoPersada.

Shafitranata. 2011. Tingkat Efisisiensi Bank Umum Syariah Menggunakan DEA (Studi Kasus Pada Bank Muamalat Indonesia, Bank Syariah Mandiri, Bank Mega Syariah Periode 2007-2010. Jakarta: Skripsi S1 UIN Syarif Hidayatullah.

Sufian, F., Mohamad, A. M. Noor, dan Muhamed-Zulkhibri, Abdul Majid. 2008. The Efficiency of Islamic Banks: Empirical Evidence from the MENA and Asian Countries Islamic Banking Sectors. Munich Personal RePEc Archive (MPRA) Paper No. 19072, Vol. 20, No. 1, Juni 2008

Suliyanto dan Purnomo Jati, Dian. 2014. Perbandingan Efisiensi Bank Perkreditan Rakyat dan Bank Umum dengan Pendekatan Data Envelopment Analysis. Jurnal Keuangan dan Perbankan, Vol. 18, No. 2, Mei 2014, hlm. 297-306

Suseno, Priyonggo. 2008. Analisis Efisiensi dan Skala Ekonomi pada Industri Perbankan Syariah di Indonesia. Jurnal Ekonomi Islam, Vol. 2 No. 1. Yogyakarta: Pusat Pengkajian dan Pembangunan Ekonomi Islam (P3EI) Fakultas Ekonomi UII. Wahab, Abdul, Hosen Muhammad N., dan Muhari, Syafaat. Komparasi Efisiensi Bank Umum Konvensional (BUK) dan Bank Umum Syariah (BUS) di Indonesia dengan Metode Data Envelopment Analysis (DEA). Al-Iqtishad: Vol. VI, No. 2, Juli 2014, hlm. 179-194

Yuniarti, Sari. 2008. Kinerja Efisiensi Bank Berstratifikasi Sesuai Dengan Visi Arsitektur Perbankan Indonesia. Jurnal Keuangan dan Perbankan. Vol. 12 No. 3 